\title{
A Cultural and Functional Approach to the Assessment of Logical Thinking Ability in English Writing
}

\author{
Cao Juan \\ Zunyi Medical and Pharmaceutical College, Zunyi 563006, Guizhou, China \\ Correspondence should be addressed to Cao Juan; 2004030328@st.btbu.edu.cn
}

Received 16 April 2021; Revised 27 April 2021; Accepted 28 April 2021; Published 1 June 2021

Academic Editor: Shah Nazir

Copyright (c) 2021 Cao Juan. This is an open access article distributed under the Creative Commons Attribution License, which permits unrestricted use, distribution, and reproduction in any medium, provided the original work is properly cited.

\begin{abstract}
The analysis of influencing factors of logical thinking ability in English writing is the key effective factor of evaluating logical thinking ability in English writing. In order to accurately evaluate logical thinking ability in English writing, this paper studies the evaluation method of logical thinking ability in English writing from the perspective of culture and function. This paper analyzes the relationship between the influencing factors of logical thinking ability in English writing. The factors of text structure and language expression reflect the culture and function of logical thinking ability in English writing, respectively, which have a direct impact on logical thinking ability in English writing. From these two aspects, 15 evaluation indexes are selected to construct the evaluation system of logical thinking ability in English writing. Considering the significant fuzziness of logical thinking ability in English writing from the perspective of culture and function, the comprehensive evaluation method of fuzzy mathematics is used for the process, the evaluation criteria are determined, the evaluation matrix is constructed, and the membership function is calculated, to complete the comprehensive evaluation of fuzzy mathematics based on the membership function and weight matrix. The experimental results show that this method can accurately evaluate the logical thinking ability of English writing and can be effectively used in the area of research.
\end{abstract}

\section{Introduction}

The word "thinking" in Chinese is synonymous with "deliberating" and "speculating." Thinking science believes that thinking is the process of people receiving information, storing information, processing information, and outputting information and generally reflects the objective reality [1]. From the essence of thinking, thinking is the conscious, indirect, and general reflection of the conscious human brain on the essential attributes and internal laws of objective reality [2]. Writing ability thinking, as far as physiological mechanism is concerned, is a writing thinking activity actively participated by trillions of cells under the action of human brain integrity; as far as the process is concerned, it is two kinds of transformation movement with opposite direction and internal unity of spiritualization of life (subjectivization of object) and lifestyle of spirit (objectivization of subject) [3]. It is a kind of directional creative thinking activity, which is the only way to sublimate understanding, dredge ideas, sort out materials, and design blueprints.

Logical thinking refers to the way of thinking that conforms to some man-made thinking rules and forms [4]. Logical thinking, also known as abstract thinking, is an advanced form of thinking. It is "a way of thinking in which people reflect reality by means of concept, judgment, and reasoning in the process of cognition. It is a thinking activity characterized by abstraction, leaving aside specific images and revealing the essential attributes of things". From the way of logical thinking, logical thinking can be divided into forward thinking, reverse thinking, divergent thinking, inductive thinking, and deductive thinking.

As a form of language output, English writing plays an important role in English learning, but it is also influenced by logical thinking to a great extent [5]. As we all know, English writing ability is one of the most difficult abilities in English learning. English writing, that is, the written expression of English, is to express certain thoughts and 
feelings through certain ideas and symbols, so as to be accepted by others. Both conception and expression have a process of logical thinking. Words are the smallest unit in language use, and concepts are called thinking cells. Notional words and phrases generally express concepts. Because words produce sentences, declarative sentences and rhetorical sentences can express statements, and product sentences can become sentence groups or logical segments. In fact, this is the process of logical proposition composed of concepts and reasoning formed by propositions [6]. Just as the famous Romanian logician Olli Wald said, logic is the common grammar of all languages and the product of language's abstract ability and generalization ability.

Chinese students are usually used to inductive thinking, which is different from deductive thinking in western society. It can be said that the logical way of thinking in English writing can, to a certain extent, reflect the writing ability, writing effect, and intelligence level of English majors [7]. In the teaching of English writing, people often only pay attention to language training but ignore the more important and fundamental training of logical thinking. As a result, there are some logical problems in writing, such as language barrier, unclear level, and unclear theme. Good English works have rigorous thinking, clear thinking, and clear context. The author must strictly abide by the basic laws of logical thinking: the law of identity, the law of contradiction, the law of excluded middle, and the law of sufficient reason. These laws require writing thinking to be definite, distinct, and argumentative from different angles.

According to the survey results of students' English writing [8], only $20 \%$ of the students who participated in the interview liked English writing, and the other $80 \%$ did not like it to some extent. The reasons they do not like include teaching methods, contents, and the exams they have to take in, but the main reason is the contents. They think that they have learned a lot, but they have "nothing to say" every time they write. Their "speechless" is that their logical way of thinking has not been well developed and guided. Their logical way of thinking has not been well guided and developed, they have not formed an effective logical way of thinking and injected appropriate ideological connotation into this way, and it is difficult to sublimate their own understanding, dredge the thinking of writing, sort out the writing materials, and design the blueprint of the article.

Lu's linear structure causality model in "Research on the influencing factors of college students' English writing ability" [9] shows that Chinese writing ability, oral English ability, and English vocabulary level have a direct impact on English writing ability, while English comprehension knowledge and ability have no direct impact on English writing ability. Marc and Alessandra put forward the "Analysis of the causes and countermeasures of college English writing function words failure" to analyze the causes of students' high pragmatic failure in the process of writing [10]. This paper argues that the main reasons are the wrong way of vocabulary acquisition, the lack of positive vocabulary, and the lack of cultural background knowledge. Arifin and Alkadri analyze "The current situation and influencing factors of college students' weariness of learning practical writing" [11] and find that, in the actual teaching, college students are generally tired of learning writing, such as fear of difficulty, burnout, anxiety, and weak interest. This paper argues that this phenomenon seriously affects the teaching effect of writing course and the quality of talent training in colleges and universities. They think that students, schools, teachers, and other factors are the main causes of this kind of weariness. The above researches in literature fully show that the analysis of influencing factors of logical thinking ability in English writing is the main influencing factor of evaluating logical thinking ability in English writing. Based on this study, the evaluation method of logical thinking ability in English writing from the perspective of culture and function is analyzed from the perspective of culture and function, the evaluation index is selected, and the comprehensive evaluation method based on fuzzy mathematics is used to obtain effective evaluation results. The following are the contributions of the study conducted:

(i) The evaluation method of logical thinking ability in English writing is studied based on culture and function perspectives.

(ii) The relationship between the influencing factors of logical thinking ability in English writing is analyzed.

(iii) 15 evaluation indexes are selected to construct the evaluation system of logical thinking ability in English writing.

(iv) Application of fuzzy mathematics is used for the process, the evaluation criteria are determined, the evaluation matrix is constructed, and the membership function is calculated, to complete the comprehensive evaluation of fuzzy mathematics based on the membership function and weight matrix.

(v) To show the effectiveness of the proposed study, experimental work has been done.

The paper is organized as follows: Section 2 is the representation of the materials and methods followed by details in subheadings. Section 3 briefly discusses the results of the study done. How to improve the thinking ability of English writing is given in Section 4 with details in subheadings. The conclusion of the paper is given in Section 5 .

\section{Materials and Methods}

2.1. The Relationship between the Influencing Factors of Logical Thinking Ability in English Writing. According to the results of relevant surveys and interviews [12], it can be found that, among many factors influencing logical thinking ability in English writing, textual structure, language expression, mode of thinking, writing psychology, and writing environment are indeed the main factors influencing English writing ability. The relationship between these main factors is shown in Figure 1.

As the previous analysis shows, among the five main factors, the mode of thinking, writing psychology, and writing environment is the "software" factors; the textual 


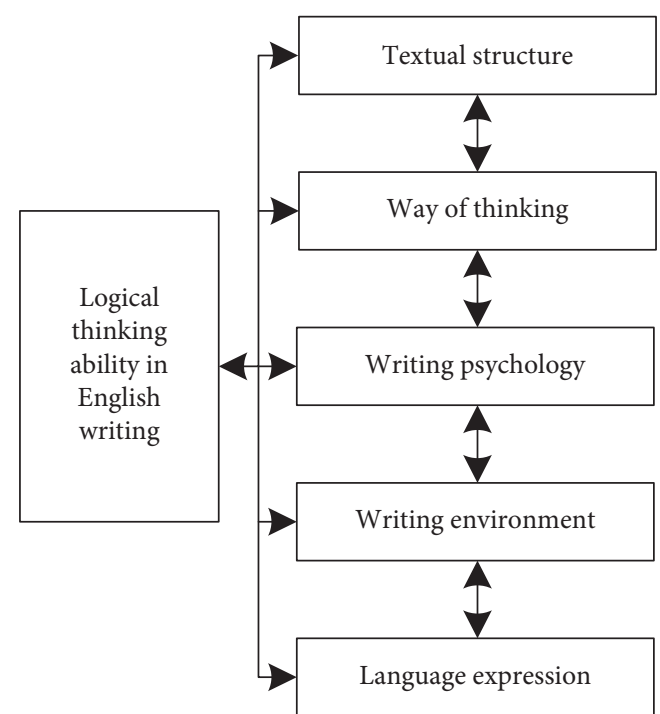

FIGURE 1: Influencing factors of logical thinking ability in English writing.

structure and language expression are the "hardware" factors. These factors are interrelated and inseparable [13]. Among them, "hardware" factors, textual structure factors, and language expression factors, respectively, reflect the culture and function of logical thinking ability in English writing, which have a direct impact on logical thinking ability in English writing. Based on these two aspects, this paper constructs an evaluation system of logical thinking ability in English writing. Considering the significant fuzziness of logical thinking ability in English writing from the perspective of culture and function, the comprehensive evaluation method of fuzzy mathematics is selected to evaluate the ability.

\subsection{Construction of Index System}

2.2.1. Selection Principle of Evaluation Index. The construction of the evaluation system of logical thinking ability in English writing should be based on promoting students' understanding of English, English writing ability, and English writing evaluation criteria [14]. In the process of evaluation, the cultural and functional evaluation of the writing process and writing results should be effectively balanced, the evaluation of the writing process should be highlighted, and the "for learning" and "as learning" of evaluation function should be given full play [15], highlighting the central position of students in the evaluation and their subjective initiative, stimulating students' self-esteem and self-confidence, enhancing their interest in learning English writing, collecting curriculum and teaching information in multilevel, multidimensional, and multichannel, scientifically analyzing, explaining, and giving feedback on evaluation results, improving students' logical thinking ability and autonomous learning ability in English writing, and effectively promoting the cultivation of students' practical ability of English academic discourse.
2.2.2. Construction of Index System. Based on the above principles, from the perspective of culture and function, this paper selects 15 evaluation indexes to construct the evaluation system of logical thinking ability in English writing, such as English vocabulary knowledge and English grammar knowledge, obeying the law of excluded middle and identity, as shown in Table 1.

Specifically speaking, from the perspective of culture, the influence of logical thinking on English writing includes four aspects: logical thinking and English writing word selection, logical thinking and English sentence making, logical thinking and paragraph construction, and logical thinking and discourse planning; from the perspective of function, the ability of logical thinking in English writing should abide by the law of excluded middle, identity, contradiction, and sufficient reason.

2.3. Comprehensive Evaluation Method Based on Fuzzy Mathematics. A comprehensive evaluation method based on fuzzy mathematics is used to evaluate the logical thinking ability of English writing from the perspective of culture and function. The specific analysis process is as follows.

2.3.1. Construction of Fuzzy Factor Set. The construction of a comprehensive evaluation factor set based on fuzzy mathematics describes the selection of representative factors that affect the logical thinking ability of English writing (i.e., the evaluation indexes in Table 1 ) as evaluation factors. $P=$ $\left\{p_{1}, p_{2}, \ldots, p_{i}, \ldots, p_{n}\right\}(i=1,2,3, \ldots, n)$ is used as the evaluation factor set based on fuzzy comprehensive of logical thinking ability of English writing and $p_{i}$ as the $i$-th evaluation factor of logical thinking ability of English writing.

2.3.2. Determination of Evaluation Criteria. $B$ is the set of logical thinking ability in English writing. The formula is $B=\left\{b_{1}, b_{2}, \ldots, b_{j}, \ldots, b_{m}\right\}(j=1,2,3, \ldots, m)$, where $b_{j}$ is the $j$-th evaluation standard. According to the standard of logical thinking ability in English writing, the $j$ value is 5 .

2.3.3. Construction of Evaluation Matrix. As the basis of constructing a comprehensive evaluation matrix of fuzzy data, membership function construction should be based on "triangular fuzzy number," "descending half trapezoidal fuzzy number," and "ascending half trapezoidal fuzzy number" [16] and refer to the ability division norms in the relevant standards of logical thinking ability in English writing to construct the membership function of logical thinking ability index factors in English writing. Based on the relevant standards of logical thinking ability in English writing [17], we can get that, in the relevant standards, the standard value of level 4 and level 5 is a critical value, which is consistent with the standard value of $Z_{i 4}$ and $Z_{i 5}$. The critical value is essentially a distinguishing value, lacking the transition between level 4 and level 5, which makes the membership function have the problem of "discontinuity" or "repetition." Some of them are actually the assessment results of logical thinking ability in English writing. The 
TABLE 1: Evaluation system of logical thinking ability in English writing.

\begin{tabular}{|c|c|c|c|}
\hline Target layer & $\begin{array}{l}\text { First level index } \\
\text { layer }\end{array}$ & Secondary index layer & Index description \\
\hline \multirow{15}{*}{$\begin{array}{l}\text { Assessment of logical } \\
\text { thinking ability in English } \\
\text { writing }\end{array}$} & \multirow{13}{*}{$\begin{array}{l}\text { From the } \\
\text { perspective of } \\
\text { culture }\end{array}$} & $\begin{array}{l}\text { Understanding vocabulary } \\
\text { knowledge in English }\end{array}$ & CET -4 basic vocabulary and CET -4 vocabulary \\
\hline & & $\begin{array}{l}\text { Understanding grammar in } \\
\text { English }\end{array}$ & $\begin{array}{c}\text { Test scores of tense, voice, congruence, structure, and } \\
\text { nonfinite verb }\end{array}$ \\
\hline & & $\begin{array}{l}\text { Understanding discourse } \\
\text { knowledge in English }\end{array}$ & $\begin{array}{c}\text { Test scores of grammatical cohesion, lexical cohesion, } \\
\text { and discourse reconstruction }\end{array}$ \\
\hline & & $\begin{array}{l}\text { English reading } \\
\text { comprehension ability }\end{array}$ & CET4 reading comprehension test scores \\
\hline & & $\begin{array}{l}\text { English listening } \\
\text { comprehension }\end{array}$ & CET4 listening comprehension test scores \\
\hline & & $\begin{array}{l}\text { English vocabulary reuse } \\
\text { ability }\end{array}$ & CET -4 basic vocabulary and CET- 4 vocabulary \\
\hline & & English grammar ability & $\begin{array}{c}\text { Test scores of tense, voice, congruence, structure, and } \\
\text { nonfinite verb }\end{array}$ \\
\hline & & $\begin{array}{l}\text { The ability of English } \\
\text { discourse reuse }\end{array}$ & $\begin{array}{c}\text { Test scores of grammatical cohesion, lexical cohesion, } \\
\text { and discourse reconstruction }\end{array}$ \\
\hline & & Oral English ability & $\begin{array}{c}\text { Reading, oral test scores, and teacher impression } \\
\text { scores }\end{array}$ \\
\hline & & English writing ability & $\begin{array}{c}\text { Composition score, number of words, and } \\
\text { superstructure score }\end{array}$ \\
\hline & & Chinese writing ability & $\begin{array}{c}\text { Composition score, number of words, and } \\
\text { superstructure score }\end{array}$ \\
\hline & & Abide by the law of exclusion & $\begin{array}{c}\text { The theme of the paper is distinct and the material } \\
\text { selection is typical }\end{array}$ \\
\hline & & Abide by the same principles & $\begin{array}{c}\text { The material and theme of the article are coordinated } \\
\text { and unified }\end{array}$ \\
\hline & \multirow{2}{*}{$\begin{array}{l}\text { From the } \\
\text { perspective of } \\
\text { function }\end{array}$} & $\begin{array}{l}\text { Abide by the law of } \\
\text { contradiction }\end{array}$ & $\begin{array}{l}\text { The level of the article is clear and the discussion is } \\
\text { consistent }\end{array}$ \\
\hline & & $\begin{array}{l}\text { Follow the law of good } \\
\text { reason }\end{array}$ & $\begin{array}{l}\text { Convincing people by reason, conclusive evidence, } \\
\text { full exposition, and satisfactory performance of the } \\
\text { theme }\end{array}$ \\
\hline
\end{tabular}

evaluation of logical thinking ability in English writing with the fifth level ability standard is obviously unable to construct the membership function (including $Z_{i 5}-Z_{i 4}=0$ ) of the fifth level ability, which is prone to the problem of deviation in the analysis results. Considering that the membership function of the fourth level ability is symmetrical to $x_{i}=Z_{i 4}$, based on the triangular fuzzy number optimization, the constraint condition $Z_{i 5}-Z_{i 4}=Z_{i 4}-Z_{i 3}$ is set, thus to construct the membership function of the fourth level ability and the fifth level ability of logical thinking in English writing.

The optimized membership function of logical thinking ability evaluation in English writing can ensure the continuity of the membership relationship between the first level ability and the fifth level ability in the process of logical thinking ability evaluation in English writing [18], which can better meet the evaluation standard of logical thinking ability in English writing. The membership function formula of the optimized logical thinking ability in English writing is described as follows.

Under the condition that $p_{i}$ belongs to the first level ability, the membership function formula is described as follows:

$$
r_{i 1}= \begin{cases}1, & x_{i} \leq Z_{i 1}, \\ \frac{Z_{i 2}-x_{i}}{Z_{i 2}-Z_{i 1}}, & Z_{i 1}<x_{i}<Z_{i 2}, \\ 0, & x_{i}>Z_{i 2} .\end{cases}
$$

Under the condition that $p_{i}$ belongs to the second level ability, the membership function formula is described as follows:

$$
r_{i 2}= \begin{cases}0, & x_{i} \leq Z_{i 1} \cup x_{i}>Z_{i 3}, \\ \frac{x_{i}-Z_{i 1}}{Z_{i 2}-Z_{i 1}}, & Z_{i 1}<x_{i} \leq Z_{i 2}, \\ \frac{Z_{i 3}-x_{i}}{Z_{i 3}-Z_{i 2}}, & Z_{i 2}<x_{i} \leq Z_{i 3} .\end{cases}
$$

Under the condition that $p_{i}$ belongs to the third level ability, the membership function formula is described as follows: 


$$
r_{i 3}= \begin{cases}0, & x_{i} \leq Z_{i 2} \cup x_{i}>Z_{i 4}, \\ \frac{x_{i}-Z_{i 2}}{Z_{i 3}-Z_{i 2}}, & Z_{i 2}<x_{i} \leq Z_{i 3}, \\ \frac{Z_{i 4}-x_{i}}{Z_{i 4}-Z_{i 3}}, & Z_{i 3}<x_{i} \leq Z_{i 4} .\end{cases}
$$

Under the condition that $p_{i}$ belongs to the fourth level ability, the membership function formula is described as follows:

$$
r_{i 4}= \begin{cases}0, & x_{i} \leq Z_{i 3} \cup x_{i}>Z_{i 5}, \\ \frac{x_{i}-Z_{i 3}}{Z_{i 4}-Z_{i 3}}, & Z_{i 3}<x_{i} \leq Z_{i 4}, \\ \frac{Z_{i 5}-x_{i}}{Z_{i 5}-Z_{i 4}}, & Z_{i 4}<x_{i} \leq Z_{i 5} .\end{cases}
$$

Under the condition that $p_{i}$ belongs to the fifth level ability, the membership function formula is described as follows:

$$
r_{i 5}= \begin{cases}0, & x_{i} \leq Z_{i 4}, \\ \frac{Z_{i 5}-x_{i}}{Z_{i 5}-Z_{i 4}}, & Z_{i 4}<x_{i} \leq Z_{i 5}, \\ 1, & x_{i}>Z_{i 5} .\end{cases}
$$

In formulas (1) to (5), $Z_{i}, x_{i}$, and $r_{i}$ denote the limits of all levels of ability standards, the actual values of logical thinking ability in English writing, and the corresponding membership degrees of different ability levels.

According to the fuzzy data, the membership degree of the evaluation factor $u_{i}$ to the evaluation set $B$ is determined. The membership degree can be expressed by $R_{i}=\left(r_{1 i}, r_{2 i}, r_{3 i}, r_{4 i}, r_{5 i}\right)$, and the fuzzy relationship from $P$ to $B$ can be expressed by $R=\left\{R_{i 1}, R_{i 2}, \ldots, R_{i j}\right\}^{T}(j=1,2,3, \ldots, n)$. By describing $R_{i}$ in the form of matrix, the following results are obtained:

$$
R=\left[\begin{array}{cccc}
r_{11} & r_{12} & \cdots & r_{1 j} \\
r_{21} & r_{22} & \cdots & r_{2 j} \\
\vdots & \vdots & \vdots & \vdots \\
r_{i 1} & r_{i 2} & \cdots & r_{i j}
\end{array}\right] .
$$

2.3.4. Building Weight Matrix. In the process of evaluating the ability of logical thinking in English writing, the importance (role, contribution, impact, etc.) of different factors $p_{i}(i=1,2,3, \ldots, n)$ in factor set $P$ is different, so it is necessary to empower the factors involved in the evaluation of the indexes [19]. There are differences in the weight values given and the level of influence on logical thinking ability in English writing. In the practical application process, the objective weighting method is often used, so the intensity contribution rate method is selected for weighting. The weighting method is a dynamic/variable weighting method, which can not only highlight the influence of the main intensity indexes but also take into account the overall influence of a single intensity indicator on the logical thinking ability of English writing. Formulas (7)-(9) are the detailed weight calculation formulas.

$$
\begin{aligned}
& w_{i}=\frac{x_{i}}{1 / 5 \sum_{j=1}^{5} Z_{i j}}, \quad(i=1,2, \ldots, n ; j=1,2, \ldots 5), \\
& \overline{w_{i}}=\frac{w_{i}}{\sum_{i=1}^{n} w_{i}}, \quad(i=1,2, \ldots, n), \\
& W=\left\{\overline{w_{1}}, \overline{w_{2}}, \ldots, \overline{w_{n}}\right\}, \sum_{i=1}^{n} \overline{w_{i}}=1 .
\end{aligned}
$$

In the above formula, $Z_{i j}$ and $w_{i}$, respectively, represent the limit values of each level of competence standard in the standard of logical thinking ability in English writing and the weight value of the normalized processing of the logical thinking ability indexes in English writing. Because $w_{i}$ can be defined as the important membership of the corresponding factors, the weight matrix $W$ can be defined as a fuzzy subset of the evaluation factor set $U$.

2.3.5. Comprehensive Evaluation of Fuzzy Mathematics. After determining $P, B$, and $R$, the rules of operation are constructed by using the weight matrix $W$ and the membership relation matrix $R$, and the membership matrix $G$ of the fuzzy comprehensive relationship between the objects of the logical thinking ability in English writing and the fuzzy comprehensive relationship of each evaluation level can be constructed.

$$
G=W \odot R=\left(a_{1}, a_{2}, \ldots, a_{j}\right) .
$$

In formula (10), $\odot$ and $a$ represent the degree values of fuzzy operation rules and the influencing factors of logical thinking ability in English writing belonging to different evaluation grades. The commonly used fuzzy operation rules include main factor determining type, weighted average type (multiplication and addition), and other operation rules [20].

\section{Results}

In order to verify the application effect of the proposed assessment method of logical thinking ability in English writing from the perspective of culture and function, 50 sophomores in an English Department of a university are randomly selected as the research objects, and the logical thinking ability in English writing of the selected subjects is evaluated by using the method of this paper. The evaluation results are as follows.

3.1. Construction of Fuzzy Factor Set. Taking the evaluation indexes in Table 1 as the main influencing factors of the 
evaluation of logical thinking ability in English writing, the fuzzy factor set is constructed.

3.2. Determination of Evaluation Criteria. The logical thinking ability of English writing is divided into five levels, as shown in Table 2.

3.3. Weight Calculation. The difference in logical thinking ability in English writing and the fuzzy relationship matrix between fuzzy factor sets are the two important assessment indicators. Based and based on this root, the weight value of each evaluation criterion of logical thinking ability in English writing is calculated. The results are shown in Table 3.

The analysis of Table 3 shows that, in the evaluation index system constructed for logical thinking ability in English writing, English writing ability is the most important factor affecting logical thinking ability in English writing; English understanding of vocabulary knowledge, English understanding of grammar knowledge, Chinese writing ability, abiding by the law of excluded middle, abiding by the law of sameness, abiding by the law of contradiction, and abiding by the law of sufficient reason are of great significance to the logical thinking ability in English writing. The weight of English vocabulary reuse ability is the lowest among the evaluation indexes; the weight of the remaining evaluation indexes is more significant.

3.4. Evaluation Results. After the evaluation of this method, we can get the comprehensive evaluation results of the logical thinking ability of the selected subjects in English writing. The comprehensive evaluation results of 10 subjects are compared with the evaluation results based on the Nemerow index and principal component analysis. The results are shown in Figure 2 and Table 4.

Figure 2 can reflect the change trend of the evaluation results of the selected study area. Because the evaluation is a quantitative method based on rank analysis, in order to describe the correlation degree between each evaluation result, rank correlation coefficient (sequential correlation coefficient) is introduced to analyze the correlation of evaluation results. The definition formula of the rank correlation coefficient between the two elements is as follows:

$$
r_{x y}^{\prime}=1-6 \sum_{i=1}^{n} \frac{d_{i}^{2}}{n\left(n^{2}-1\right) d_{i}^{2}}=\left(R_{1 i}-R_{2 i}\right)^{2} .
$$

In formula (11), $r_{x y}{ }^{\prime}$ is the rank correlation coefficient of the two indexes and $d_{i}^{2}=\left(R_{1 i}-R_{2 i}\right)^{2}$ is the square of the difference between the two indexes in the same group of samples.

According to the results of rank correlation analysis in Table 4, it is found that the rank correlation coefficients of the proposed method with fuzzy operation rule determined by main factors, the proposed method with fuzzy operation rule determined by weighted average, and the evaluation method based on Nemerow index and the evaluation method based on principal component analysis are 0.719,
TABLE 2: Results of logical thinking in English writing.

\begin{tabular}{lc}
\hline Gradation & Classification criteria \\
\hline Level 1 capability & The composite index is above 80 \\
Level 2 capability & The composite index is between 60 and 80 \\
Level 3 capability & The composite index is between 40 and 60 \\
Level 4 capability & The composite index is between 20 and 40 \\
Level 5 capability & The composite index is below 20 \\
\hline
\end{tabular}

TABLE 3: Calculation results of weight values of different influencing factors.

\begin{tabular}{lc}
\hline Evaluating indicator & Weight \\
\hline Understanding vocabulary knowledge in English & 0.072 \\
Understanding grammar in English & 0.093 \\
Understanding discourse knowledge in English & 0.049 \\
English reading comprehension ability & 0.047 \\
English listening comprehension & 0.041 \\
English vocabulary reuse ability & 0.039 \\
English grammar ability & 0.040 \\
The ability of English discourse reuse & 0.041 \\
Oral English ability & 0.069 \\
English writing ability & 0.132 \\
Chinese writing ability & 0.083 \\
Abide by the law of exclusion & 0.075 \\
Abide by the same principles & 0.072 \\
Abide by the law of contradiction & 0.071 \\
Follow the law of good reason & 0.076 \\
\hline
\end{tabular}

0.690 , and 0.550 , respectively (when the confidence level (both sides) is 0.01 , there is a very significant correlation). This shows that the above four evaluation methods can be used to evaluate the logical thinking ability of English writing.

Table 5 shows the statistical table of logical thinking evaluation results of 50 subjects' English writing ability.

It can be seen from Table 5 that the number of research objects in level 4 and level 5 is consistent according to the evaluation results of the proposed method under two different fuzzy operation rules, while the number of research objects in level 1 ability evaluation is gradually increased as the following order: the fuzzy operation rule of the proposed method determined by the main factor $\longrightarrow$ the fuzzy operation rule of the method determined by the weighted average $\longrightarrow$ the evaluation method based on principal component analysis $\longrightarrow$ the evaluation methods based on Nemerow index; the number of research objects in level 2 ability evaluation is gradually decreased as the following order: the fuzzy operation rule of the proposed method determined by the main factor $\longrightarrow$ the fuzzy operation rule of the method determined by the weighted average $\longrightarrow$ the evaluation methods based on principal component analysis $\longrightarrow$ the evaluation methods based on Nemerow index; the number of research objects in level 3 ability evaluation is gradually decreased as the following order: the fuzzy operation rule of the proposed method determined by the main factor $\longrightarrow$ the fuzzy operation rule of the method determined by the weighted average $\longrightarrow$ the evaluation method based on Nemerow index $\longrightarrow$ the evaluation method based on principal component analysis. The results show that the 


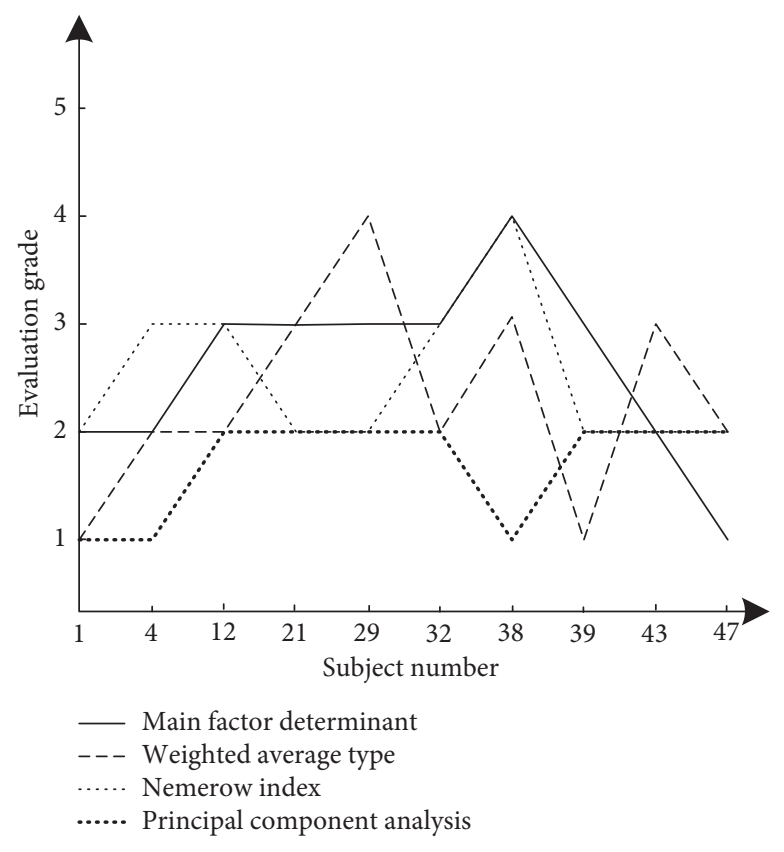

Figure 2: Membership chart of different research objects.

TABLE 4: Rank correlation coefficient of evaluation type $(n=50)$.

\begin{tabular}{|c|c|c|c|c|}
\hline Evaluation method & $\begin{array}{c}\text { The method of this paper } \\
\text { (main factor determining } \\
\text { type) }\end{array}$ & $\begin{array}{l}\text { The method of this } \\
\text { paper (weighted } \\
\text { average type) }\end{array}$ & $\begin{array}{c}\text { Evaluation method } \\
\text { based on Nemerow } \\
\text { index }\end{array}$ & $\begin{array}{c}\text { Evaluation method based } \\
\text { on principal component } \\
\text { analysis }\end{array}$ \\
\hline $\begin{array}{l}\text { The method of this paper } \\
\text { (main factor determining } \\
\text { type) }\end{array}$ & 1.000 & & & \\
\hline $\begin{array}{l}\text { The method of this paper } \\
\text { (weighted average type) }\end{array}$ & $0.719^{* *}$ & 1.000 & & \\
\hline $\begin{array}{l}\text { Evaluation method based on } \\
\text { Nemerow index }\end{array}$ & $0.657^{* *}$ & $0.690^{* *}$ & 1.000 & \\
\hline $\begin{array}{l}\text { Evaluation method based on } \\
\text { principal component } \\
\text { analysis }\end{array}$ & $0.625^{* *}$ & $0.591^{* *}$ & $0.550^{* *}$ & 1.000 \\
\hline
\end{tabular}

TABLe 5: Statistical table of evaluation results $(n=50)$.

\begin{tabular}{lcccc}
\hline $\begin{array}{l}\text { Evaluation } \\
\text { grade }\end{array}$ & $\begin{array}{c}\text { The method of this paper (main } \\
\text { factor determining type) }\end{array}$ & $\begin{array}{c}\text { The method of this paper } \\
\text { (weighted average type) }\end{array}$ & $\begin{array}{c}\text { Evaluation method based } \\
\text { on Nemerow index }\end{array}$ & $\begin{array}{c}\text { Evaluation method based on } \\
\text { principal component analysis }\end{array}$ \\
$\begin{array}{l}\text { Level 1 } \\
\text { capability }\end{array}$ & 6 & 9 & 20 & 10 \\
$\begin{array}{l}\text { Level 2 } \\
\text { capability }\end{array}$ & 28 & 24 & 6 & 19 \\
$\begin{array}{l}\text { Level 3 } \\
\text { capability }\end{array}$ & 9 & 8 & 7 & 5 \\
$\begin{array}{l}\text { Level 4 } \\
\text { capability }\end{array}$ & 6 & 6 & 2 & 5 \\
$\begin{array}{l}\text { Level 5 } \\
\text { capability }\end{array}$ & 1 & 1 & 2 & 5 \\
\hline
\end{tabular}

evaluation accuracy of the method based on two different fuzzy operation rules and the evaluation method based on the Nemerow index is better than that based on principal component analysis. The evaluation results of the proposed method under two different fuzzy operation rules are different from those of the Nemerow index evaluation method due to the improved membership function. The reason is that the Nemerow index evaluation method has 
discontinuous critical values, which cannot represent the real logical thinking ability of English writing. On the whole, the evaluation results obtained by the proposed method are better than those obtained by the two comparative methods.

It can be seen from Table 4 that the rank correlation coefficient of the proposed method with weighted average as fuzzy operation rule reaches 0.719 , which indicates that this method is superior to other methods in the evaluation of logical thinking ability in English writing. However, due to the existence of overlapping budget in this method with the main factor as fuzzy operation rule, it is easy to cover up the influence of English writing ability on logical thinking ability in English writing. When some indexes are especially large, it is easy to cause unreasonable comprehensive evaluation results, while the weighted average type can retain all or most of the information in the index vector as far as possible, which solves the problem of the failure of the maximum clustering coefficient principle to a certain extent, and has the characteristics of positive laterality, single increment, continuity, and additivity, comprehensively reflecting the effect of a single index on the overall evaluation. The effect of fruit can reasonably reflect the comprehensive influence of all indexes.

\section{How to Improve the Thinking Ability of English Writing?}

4.1. Typed Writing Training. In order to cultivate students' good English writing habits, the first step is to improve students' ability of writing layout and strengthen their understanding of the differences between English and Chinese texts. There are two kinds of text exercises: one is outline writing, in which students write a detailed outline of the given topic; the other is sorting exercise, in which students choose a passage written by British and American people, delete the conjunctions, disrupt the sentence order, and ask students to reorder and add conjunctions to indicate logical relations. This exercise helps students to understand the logical habits of English writing. Contrast exercise is a combination of sentence construction and text training. Firstly, excellent English model articles and extract Chinese outline are selected. On this basis, students write independently. Then, students are asked to compare the model articles and find out the logical defects of their compositions.

4.2. Specific Writing Topics. The number of words required in College English writing practice is generally about 200 words, which determines that the content is extremely limited and the topic is too wide, which will directly affect the quality of writing. Therefore, teachers should select topics to make them more suitable for students' writing practice. Taking the writing exercise "My Thoughts on Environmental Protection" as an example, there are too many contents that can be written, and the scope should be narrowed. It can be modified to "My Thoughts on Environmental Protection on Campus/of Yang zi River/in the Age of Internet" and so on. For example, the composition of Unit 3 in Volume 1 is "How Science Changes Our Lives," and we may as well refine the writing requirements and let students choose a specific scientific invention and explore its impact on life more deeply. It can also effectively avoid the common problems of students' composition, such as scattered center and empty content.

4.3. Modular Evaluation Method. The main content of the College English writing course consists of six steps: making clear the goal of practice, determining the proposition and requirement, assigning writing tasks, teaching writing strategies and skills, guiding students' practice, and reviewing compositions and teachers' feedback. The last two steps are easy to ignore. The feedback that students get often only contains the overall impression scores given by teachers and the grammar problems that they randomly tick out. They cannot fundamentally understand the problems in their compositions, and the practice effect cannot be guaranteed. In recent years, great progress has been made in the computerization and networking of composition evaluation methods in foreign countries. PEG, e-rater, IEA, and other automatic scoring systems have been well applied. However, there is no mature, for English composition evaluation in Chinese context. Clear scoring rules and advanced means of evaluation can smooth the communication between teachers and students and improve the effect of writing teaching. In terms of scoring rules, it is suggested to adopt the six-point method to classify and consider logic, content, sentence construction, grammar, vocabulary, and operation details, score items, and give specific feedback. Office software and e-mail system provide favorable tools for modularization of writing assessment, which can make the steps of marking clearer and more fluent. Students use word documents to write compositions. The error correction function of the software helps to correct simple spelling and punctuation errors. The selfrating reflects the quality of operation details. The preliminary revised articles are sent to the students in the study group by e-mail. The second step is to evaluate the use of basic grammar and vocabulary, encourage the students in the same group to evaluate each other after group discussion, score each item, and make corrections with comments. After the completion of the mutual evaluation, it is sent to the teacher for review above the language level, giving specific modification opinions and scores in logic, content and sentence construction, and then returning to the evaluation group and the author; the fourth step of the evaluation is the students' rewriting and second submission; the fifth step is to review the final draft, evaluate whether the modification is appropriate, score and establish the learner file from six angles again, record the scores of two rounds of each exercise in detail, save the copy of the composition, and master the learning effect of the students; finally, give feedback on the comments, final draft, and model to the students.

\section{Conclusion}

English writing requires the expression of clear and complete ideas. The purpose of writing teaching is to improve students' ability to express ideas in English. And "thought 
poverty" and "critical crisis" have become the true portrayal of English majors' writing. Under this background, this paper studies the evaluation method of logical thinking ability in English writing from the perspective of culture and function, selects the evaluation index from the perspective of culture and function, constructs the evaluation system, and obtains the effective evaluation results by using the comprehensive evaluation method of fuzzy mathematics. It is expected that this method can effectively improve students' English writing ability.

\section{Data Availability}

The datasets used and/or analyzed during the current study are available from the corresponding author on reasonable request.

\section{Conflicts of Interest}

The author declares that he has no conflicts of interest.

\section{References}

[1] B. María-José, G. D. Héctor, and M. Poblete, "Importance and possibilities of development of critical thinking in the university: the teacher's perspective," Multidisciplinary Journal of Educational Research, vol. 11, no. 1, 20 pages, 2021.

[2] A. Rakhmawan, H. Firman, S. Redjeki, and S. Mulyani, "Contribution of logical thinking ability to students' achievement in three level of representations in chemical dynamic materials," Jurnal Penelitian Dan Pembelajaran IPA, vol. 4, no. 2, 116 pages, 2018.

[3] S. Andriani, E. Nurlaelah, and K. Yulianti, "The effect of process oriented guided inquiry learning (pogil) model toward students' logical thinking ability in mathematics," Journal of Physics Conference Series, vol. 1157, no. 4, Article ID 04, 2019.

[4] S. Murni, S. Ruqoyyah, and L. H. Fasha, "Analysis of mathematical thinking skills in multiple intelligence perspectives of primary school students," Journal of Physics: Conference Series, vol. 1657, no. 1, Article ID 012013, 2020.

[5] H. Riyanti, S. Suciati, S. Suciati, and P. Karyanto, "Enhancing student' logical-thinking ability in natural science learning with generative learning model," Biosaintifika: Journal of Biology \& Biology Education, vol. 10, no. 3, pp. 648-654, 2018.

[6] D. Cabral and C. Sales, "Contributions and implications of the dialogical perspective: the therapist's self in the family/couple therapy," Nova Perspectiva Sistêmica, vol. 28, no. 63, pp. 2141, 2019.

[7] R. Rahmawati, N. Y. Rustaman, I. Hamidah, and D. Rusdiana, "The profile of cognitive style, logical thinking ability, and conceptual knowledge of electricity and magnetism topic based on prospective physics teachers' grade level," Journal of Physics: Conference Series, vol. 1157, no. 3, Article ID 032036, 2019.

[8] S. Gröschl and P. Gabaldon, "Business schools and the development of responsible leaders: a proposition of edgar morin's transdisciplinarity," Journal of Business Ethics, vol. 153, no. 1, pp. 185-195, 2018.

[9] Y.X. Lu, "The exploration of university practical teaching and supporting evidence from the perspective of ability training-illustrated in the case of Heilongjiang provincial $h$ university social work major," Journal of Heilongjiang Institute of Technology, vol. 33, no. 3, pp. 73-76, 2019.

[10] B. Marc, C. Alessandra, C. Alessandra, and W. Kerstin, "The function of personality in suicidal ideation from the perspective of the interpersonal-psychological theory of suicide," International Journal of Environmental Research \& Public Health, vol. 15, no. 4, pp. 636-638, 2018.

[11] R. Arifin, R. Alkadri, D. P. Sari, L. Resthiningsih, and A. M. Holish, "Improving law student ability on legal writing through critical and logical thinking by irac method," Indonesian Journal of Advocacy and Legal Services, vol. 1, no. 1, pp. 107-128, 2019.

[12] S. Yang, M. Guo, X. Liu, P. Wang, Q. Li, and H. Liu, "Highway performance evaluation index in semiarid climate region based on fuzzy mathematics," Advances in Materials Science and Engineering, vol. 2019, no. 2, pp. 1-7, 2019.

[13] N. Wang, "A comparative study of folk culture translation from the perspective of cultural presupposition-taking four English versions of biancheng as an example," Open Access Library Journal, vol. 7, no. 5, pp. 1-9, 2020.

[14] M. Khoroshukha, A. Bosenko, S. Prysiazhniuk, O. Tymchyk, and J. Nevedomsjka, "Influence of sexual dimorphism on the development of the logical thinking function in young athletes aged 13-15 years with different blood groups," Georgian Medical News, vol. 309, pp. 108-114, 2020.

[15] C. H. Peng, "Simulation of optimal feature detection and location method under chaotic data structure," Computer Simulation, vol. 35, no. 3, pp. 345-380, 2018.

[16] J. Yuan, W. Li, B. Xia, Y. Chen, and M. J. Skibniewski, "Operation performance measurement of public rental housing delivery by ppps with fuzzy-ahp comprehensive evaluation," International Journal of Strategic Property Management, vol. 23, no. 5, pp. 328-353, 2019.

[17] H. Quanhua, Z. Wenting, L. Xuanye, and Z. Xuan, "Urban ecosystem health assessment inside Xi'an by multivariate data," Journal of Environmental Protection and Ecology, vol. 19, no. 3, pp. 1016-1025, 2018.

[18] S. R. Manurung and D. D. Panggabean, "The identification of logical thinking ability based on gender in physics teachers prospective students," Journal of Community Research and Service, vol. 2, no. 1, 192 pages, 2018.

[19] H. Riyanti, S. Suciati, and P. Karyanto, "The effectiveness of generative learning model to enhance students' logicalthinking ability in science learning," EDUSAINS, vol. 10, no. 2, pp. 309-318, 2018.

[20] A. Bahtiar, A. Syamsuddin, and I. Akib, "Description of mathematical communication skills, logical thinking and its influence on the ability of mathematical literacy for students of grade v elementary school," International Journal of Scientific \& Technology Research, vol. 9, no. 4, pp. 1075-1078, 2020. 